\title{
A ontologia espinosista de Deleuze: univocidade, imanência, diferença
}

Deleuze's Spinozian ontology:

univocity, immanence, difference

MARIANA DE TOLEDO BARBOSA (iD ${ }^{a}$

\section{Resumo}

Na filosofia de Gilles Deleuze, há uma ontologia, que é apresentada por meio da tese da univocidade do ser. Na história da filosofia ocidental, Deleuze destaca três momentos da univocidade do ser: com Duns Scot, o ser é pensado como unívoco (momento da univocidade); com Espinosa, o ser é afirmado como unívoco (momento da imanência); com Nietzsche, o ser é realizado como unívoco (momento da diferença). Em todo caso, a univocidade é uma alternativa à analogia, e a principal discordância entre essas duas teses é que a analogia insere uma hierarquia e uma negatividade no cerne do ser, ao passo que a univocidade põe o ser como igual (nãohierárquico) e isento de negatividade (neutro ou afirmativo).

Neste artigo, não se trata de apresentar a teoria da univocidade do ser em Deleuze, mas de explorar a leitura que ele faz da univocidade do ser em Espinosa, e sobretudo a variação a ela imposta entre o primeiro e o segundo livros dedicados ao filósofo holandês, Espinosa e o problema da expressão (1968) e Espinosa: filosofia prática (1981). Constata-se que, no primeiro estudo, Espinosa é tido principalmente como herdeiro de Duns Scot, e no segundo, ademais, como aliado de Nietzsche. Tem-se como hipótese que Espinosa é arrastado, nesse ínterim, do segundo para o terceiro momento da univocidade do ser, na vassoura de bruxa de Deleuze. A consequência é que a imanência e a afirmação se conciliam com a diferença. A afirmação do ser passa a ser afirmação da própria diferença. Ou, dito de outro modo, o ser deixa de ser apenas afirmado para ser realizado como diferença. Chega-se, assim, a uma ontologia construtivista, que tem a ética como sua condição prática.

Palavras-chave: Gilles Deleuze. Baruch Espinosa. Ontologia. Univocidade do ser. Diferença.

\footnotetext{
a Universidade Federal Fluminense (UFF), Niterói, RJ, Brasil. Doutora em Filosofia, e-mail: mari_tb@hotmail.com
} 


\section{Abstract}

There is an ontology in Gilles Deleuze's philosophy, which is presented by means of his reading of the thesis of the univocity of being. Deleuze highlights three moments of univocity of being in Western philosophy: with Duns Scot, Being would be thought as univocal (univocity); with Spinoza, Being would be affirmed as univocal (immanence); with Nietzsche, Being would be realized as univocal (difference). In any case, univocity appears as an alternative to analogy, and the main noncorformity between these two thesis is that analogy is hierarchical and includes negativity in the core of Being whereas univocity approaches Being as equal (non-hierarchical) and non-negative (either neutral or affirmative).

In this article, we do not intend to present the thesis of the univocity of being in Deleuze, but only to explore his reading of the Spinozistic univocity of being, and, above all, the variation it suffers between the first and second books dedicated to the Dutch philosopher, Expressionism in Philosophy: Spinoza (1968) and Spinoza: Practical Philosophy (1981). We verify that, in the first of these studies, Spinoza is considered a heir of Duns Scot, but in the second, an ally to Nietzsche as well. Our hypothesis is that Spinoza is dragged on Deleuze "witch broom", in the meantime, from the second to the third moments of the univocity of being. Hence immanence and affirmation reconcile with difference. Affirmation becomes affirmation of difference itself. In other words, Being is no longer strictly affirmed, but realized as difference. One attains thus a constructivist ontology, with ethics as its practical condition.

Keywords: Gilles Deleuze. Baruch Spinoza. Ontology. Univocity of being. Difference.

\section{Introdução: um só ou vários Espinosas?}

$\mathrm{Na}$ filosofia de Gilles Deleuze, há uma ontologia1. Em Diferença e repetição, esta ontologia é inseparável da diferença. Mas antes mesmo de dizer que o ser é diferença, é necessário a Deleuze sustentar que ele é unívoco, ou seja, igual e isento de negatividade. Segundo esses critérios, ele alinha os pensadores nas teses ontológicas da analogia, que toma o ser como hierárquico ou dotado de negatividade, ou da univocidade, que estabelece que o ser é igual e neutro ou afirmativo.

A analogia do ser, que se inicia com Aristóteles lido à luz de São Tomás de Aquino, insere uma hierarquia no ser e implica o modelo do juízo. O ser é equívoco,

\footnotetext{
${ }^{1}$ A ontologia de Deleuze já suscitou muitas polêmicas e interpretações diversas. Na recepção francesa de sua obra, por exemplo, podem ser citadas as diferentes posições encontradas nos livros de Badiou (1997), Zourabichvili (1994/2004) e Montebello (2008). No Brasil, Craia (2002) dedicou um livro inteiro ao tema.
} 
análogo e eminente: não se diz no mesmo sentido, mas em sentido análogo, da substância divina (incriada) e das substâncias criadas, e os atributos encontrados nas criaturas são ditos preexistir eminentemente em Deus. Até mesmo nas coisas, o ser se diz em diversos sentidos hierarquicamente distintos: de diversas categorias. Essa hierarquia do ser permite o julgamento das coisas. A analogia das essências de Leibniz e Hegel, em compensação, insere a negatividade no ser e traz o modelo da proposição: as coisas, ao invés de julgadas a partir de uma hierarquia no ser, são tomadas como proposições que abarcam a negação. Nas proposições sintéticas de Hegel, as essências têm como condição um negativo de contradição; nas proposições analíticas de Leibniz, as essências derivam de um negativo de limitação. (DELEUZE,1968a, p. 55-61, p. 70-79; 1968b, p. 55-64)

Quanto à univocidade do ser, Deleuze (1968a, p. 66-69) destaca seus três grandes momentos na história da filosofia ocidental: no primeiro, Duns Scot inaugura a tradição, pensando o ser unívoco como neutro e abstrato; no segundo, Espinosa afirma o ser unívoco, retirando-o de sua neutralidade e dando uma nova versão para a univocidade, a saber, a imanência; no terceiro, Nietzsche realiza o ser unívoco, fazendo com que este não apenas se afirme, mas se afirme da própria diferença. Cada um destes autores impõe uma modificação à tese da univocidade do ser e recusa a tese ontológica da analogia, seja ela do ser ou das essências. A tradição da univocidade toma o ser como neutro ou afirmativo (não-negativo) e como igual (não-hierárquico). “[...] a univocidade do ser significa também a igualdade do ser" (DELEUZE, 1968a, p. 64). E caso levada às últimas consequências, a univocidade realiza o ser como diferença.

Nada surpreendente, pois, que Deleuze valorize a univocidade. Um pouco desconcertante talvez que, para isso, se sirva da filosofia de Espinosa, transformando este filósofo inicialmente em herdeiro de Duns Scot e posteriormente em aliado de Nietzsche. Eis então que vemos a imanência de Espinosa afetada ora pela univocidade, em Espinosa e o problema da expressão, ora pela diferença, em Espinosa: filosofia prática, e já não temos um, mas vários Espinosas.

Talvez a pista para se compreender a passagem do primeiro para o segundo momento esteja em Diferença e repetição. Ali se encontra algo como uma ressalva à ontologia espinosista. Poucas páginas depois de sustentar que a única proposição 
ontológica que já existiu foi “o Ser é unívoco" e elencar os três momentos da univocidade do ser, situando Espinosa na segunda posição, Deleuze (1968a, p. 68) aponta que a ontologia de Espinosa é limitada pela indiferença entre a substância e os modos: "a substância espinosista aparece independente dos modos, e os modos dependendo da substância, mas como de outra coisa”. De acordo com Deleuze, a ontologia espinosista apenas afirma a univocidade do ser porque são os modos que se dizem da substância. Para que a univocidade do ser fosse realizada, e não somente afirmada, seria necessário que a substância se dissesse dos modos. Não daria assim Deleuze uma indicação de como se apropria da ontologia espinosista? Não seria essa a operação que ele próprio faz na passagem do primeiro para o segundo de seus livros sobre Espinosa?2

\section{Expressão, univocidade e imanência em Espinosa e o problema da expressão}

Em seu primeiro livro sobre Espinosa, Deleuze lê sua filosofia à luz do problema da expressão. Ao abordar a ontologia espinosista, chega à afirmação de um ser expressivo. Acrescenta ainda que o ser expressivo é necessariamente unívoco, e que a fórmula da univocidade em Espinosa é a imanência. Liga, deste modo, três importantes aspectos da ontologia espinosista: a expressão, a univocidade e a imanência.

O problema da expressão já aparece em Espinosa desde a definição 6 da parte I da Ética: "Por Deus entendo o ente absolutamente infinito, isto é, a substância que consiste em infinitos atributos, cada um dos quais exprime uma essência eterna e infinita." Desta definição, Deleuze (1968b, p. 29-41) extrai a primeira tríade da expressão, que inclui a substância, o atributo e a essência: a substância se expressa, o atributo é expressão, a essência é expressa. Dizer que o ser é expressivo é, antes de mais nada, afirmar que a substância única, que é o ser em si, o ser enquanto ser, se expressa. E ela se expressa em seus atributos: os atributos são expressões da substância.

\footnotetext{
${ }^{2}$ Machado (2009, p. 86) sustenta que a crítica feita à univocidade do ser em Espinosa serve para situá-lo, já em Diferença e repetição, na perspectiva de Nietzsche.
} 
Para Espinosa, os atributos são as qualidades da substância. Destas, percebemos duas: o pensamento e a extensão. Mas há infinitas qualidades, infinitos atributos. As qualidades da substância constituem a essência, ou natureza, da substância. Por isso Espinosa afirma que a substância consiste em infinitos atributos. Além de qualidades, os atributos são formas, o que remete a um tipo de distinção que Deleuze confere a Espinosa, mas que surge na Idade Média, com Duns Scot.

A distinção formal de Duns Scot é recuperada por Deleuze (1968b, p. 29-41) em sua tentativa de explicar a conciliação entre uma única substância e os infinitos atributos em Espinosa. A primeira pergunta que surge é: como a diversidade de atributos não divide a substância? Em Descartes, por exemplo, as substâncias se distinguem por seus atributos, e assim temos uma substância pensante e uma substância extensa. Em Espinosa, ao contrário, há uma única substância, que tem como um de seus atributos o pensamento, como outro, a extensão, e infinitos atributos além destes. Mas então vem a segunda pergunta: se esses infinitos atributos são atributos de uma mesma substância, como eles se distinguem? Justamente, eles não se distinguem numericamente ou quantitativamente, pois, neste caso, dividiriam a substância, e não mais teríamos a substância única espinosista. Eles se distinguem formalmente ou qualitativamente: a substância única tem infinitas formas, infinitas qualidades, que são como pontos de vista internos sobre a substância. A substância é percebida como extensa do ponto de vista do atributo extensão, como pensante do ponto de vista do atributo pensamento, segundo perspectivas internas diversas sobre a mesma substância única. A substância é ontologicamente ou quantitativamente una e formalmente ou qualitativamente diversa. A distinção real, que diz respeito ao ser enquanto ser, não é uma distinção numérica ou quantitativa, mas uma distinção formal, qualitativa. Deleuze (1968b, p. 40-41) sustenta que, apesar de Espinosa lançar mão da terminologia cartesiana ao falar em distinção real, o que se encontra por trás deste termo é a distinção formal de Duns Scot, que conquista um alcance ainda maior no espinosismo.

Portanto, a substância única se expressa em seus infinitos atributos. Mas o que estes atributos, que são expressões, expressam? Segundo a definição 6 da parte I da Ética, cada atributo expressa uma essência eterna e infinita. A tríade da expressão encontra seu terceiro termo: a essência, que, apesar de ser expressa pelo atributo, 
não é essência do atributo, mas da substância. Eis a tríade completa: a substância se expressa nos atributos, os atributos são expressões, a essência (da substância) é expressa. Mas se cada atributo expressa uma essência, e há diversos atributos, então há diversas essências da substância? Isso não reintroduziria uma divisão na substância, ameaçando mais uma vez sua unicidade? A distinção formal nos presta auxílio novamente: a essência da substância é ontologicamente ou quantitativamente una, formalmente ou qualitativamente diversa. Cada atributo expressa uma essência qualificada, mas todas essas qualidades são atribuídas à mesma essência, à essência da substância (DELEUZE, 1968b, p. 15-48).

O ser expressivo implica ainda uma segunda tríade, pois a substância se reexpressa: há uma expressão da expressão, que se dá uma vez que o atributo se expressa. E ele se expressa em seus modos, que são quantidades ou graus de intensidade das qualidades. Os atributos são qualidades, e os modos são quantidades ou graus de intensidade destas qualidades, distinguindo-se entre si quantitativamente, numericamente. Se a distinção real entre os atributos da substância é formal e qualitativa, a distinção modal entre os modos de cada atributo é numérica, quantitativa. Em Duns Scot, há um ótimo exemplo para entender a relação entre a qualidade e a quantidade: para a qualidade branco, há uma diversidade de graus diferentes. O branco é mais ou menos intenso segundo o grau ou a quantidade. Em Espinosa, há, em cada qualidade, em cada atributo, uma diversidade de graus de intensidade, uma multiplicidade de modos que se distinguem numericamente, quantitativamente entre $\mathrm{si}^{3}$ (DELEUZE, 1968b, p. 15-17, p. 209-219).

Voltando à segunda tríade, os atributos se expressam, os modos são expressões, mas o que os modos expressam? Uma modificação da substância. Cada modificação da substância é expressa por um modo, em cada um dos infinitos atributos. Cada um destes modos, em cada um dos infinitos atributos, são expressões de uma mesma modificação da substância. É neste sentido que, em Espinosa, corpo e mente expressam a mesma coisa, ou seja, a mesma modificação da substância, só que percebida a partir de dois pontos de vista distintos, a partir de

\footnotetext{
${ }^{3}$ Chauí (2014, p. 39) destaca que a originalidade da leitura deleuziana repousa justamente na utilização da teoria medieval dos graus e do modo intrínseco para responder ao problema da existência dos seres singulares na filosofia de Espinosa.
} 
dois atributos diversos. O corpo é um modo do atributo extensão, a mente é um modo do atributo pensamento, mas corpo e mente expressam a mesma modificação da substância. Deleuze (1968b, p. 107-120) adota um termo de Leibniz para conceber essa relação entre modos que expressam a mesma modificação da substância: paralelismo. Contudo, diferentemente de outros comentadores de Espinosa, entende o paralelismo espinosista como, além de uma identidade de ordem e de conexão, uma identidade ontológica entre estes modos. Portanto, dizer que corpo e mente são paralelos inclui dizer que são idênticos ontologicamente ${ }^{4}$.

Essas duas tríades da expressão reúnem a expressão e a reexpressão da substância: a primeira expõe a constituição da essência da substância pelos seus infinitos atributos; a segunda, a produção dos modos pela substância em seus infinitos atributos. Ao se expressar em seus atributos, a essência da substância é expressa, e a substância se constitui como natureza naturante, que tem infinitos atributos. Ao se reexpressar nos modos, uma modificação da substância é expressa, e a substância produz a natureza naturada em seus atributos, engendra os modos contidos em seus infinitos atributos. Na primeira tríade, a substância é causa de si ao constituir a própria essência; na segunda, é causa dos modos ao produzi-los em seus atributos. É então uma causa imanente: permanece em si ao produzir, e seus efeitos não saem dela (DELEUZE, 1968b, p. 15-17, p. 187-205).

Apesar de produzir os modos, que são seus efeitos, e de esses efeitos não saírem de sua causa, da substância, não há qualquer confusão entre a essência da substância e as essências dos modos. O que garante a distinção entre a essência da substância e as essências dos modos é o atributo. Os atributos, como já vimos na primeira tríade da expressão, são as qualidades que constituem a essência da substância única; e, na segunda tríade da expressão, os modos, em suas essências, são produzidos nesses atributos, como graus de intensidade dessas qualidades. São os mesmos atributos, as mesmas formas, as mesmas qualidades, que constituem a essência da substância e contêm as essências dos modos.

\footnotetext{
${ }^{4}$ Deleuze (1968b, p. 117) chega a dizer que o próprio Leibniz não deu todo o alcance ao paralelismo, que só se reveste de seus três aspectos - identidade de ordem, de conexão e ontológica - em Espinosa.
} 
Dos infinitos atributos, percebemos apenas dois: o pensamento e a extensão. Percebemos somente estes dois porque os implicamos em nossa essência: somos mente e corpo, um modo do atributo pensamento e um modo do atributo extensão. Mas a extensão implicada em nosso corpo e o pensamento implicado em nossa mente são a mesma extensão e o mesmo pensamento que constituem a essência da substância. Esta comunidade de formas entre a substância e os modos - o fato de os mesmos atributos constituírem a essência da substância e conterem as essências dos modos -, é chamada, por Deleuze, de univocidade dos atributos (DELEUZE, 1968b, p. 51-52, p. 62-66).

A univocidade (ou identidade) dos atributos se prolonga na univocidade (ou unidade) da causa. A causa de tudo que é se diz no mesmo sentido do que é causa: da substância como única causa de todas as essências, da sua própria e das dos modos. Todavia, a causa se diz em sentidos diferentes: quando causa de si, a substância é causa formal, quando causa dos modos, é causa eficiente (DELEUZE, 1968b, p. 182-185). Na primeira tríade da expressão, a substância é causa da sua própria essência, da sua própria natureza; na segunda, ela é causa das coisas, das essências dos modos.

Segundo Deleuze (1968b, p. 55-71), Espinosa defende que apenas os atributos expressam a natureza de Deus (ou da substância), em ruptura com tradições teológicas anteriores que em geral confundem a natureza de Deus com meras propriedades e acabam erigindo, mesmo que a contragosto, um Deus antropomórfico. Assim, Deus se expressa em seus atributos, dos quais percebemos o pensamento e a extensão, e se (re)expressa nos modos. Ele sempre se expressa afirmativamente e atualmente: nada nega, nada oculta, nada reserva para uma futura produção. E sempre expressa sua própria natureza (natureza naturante), o que inclui a produção dos modos (natureza naturada). Não há modos que Deus reserve para produzir futuramente: em sua absoluta perfeição, produz tudo o que concebe. Consequentemente, não há possível na Natureza: tudo é atual. Deus é a substância que constitui a si mesma e que produz os modos, é pura expressão, e expressão sempre afirmativa: se expressa e se afirma tanto na constituição de si quanto na produção dos modos. Os atributos de Deus são expressivos e unívocos, dizendo-se de Deus e das criaturas, da substância e dos modos. "Os atributos são afirmações. 
Mas a afirmação, em sua essência, é sempre formal, atual, unívoca: é neste sentido que ela é expressiva." (DELEUZE, 1968b, p. 63).

Com efeito, Deleuze sustenta que há uma afirmação pura da univocidade do ser em Espinosa, além de uma nova fórmula, a imanência, que reúne a univocidade dos atributos e a univocidade da causa.

\begin{abstract}
Em Espinosa [...], o Ser unívoco é perfeitamente determinado no seu conceito, como o que se diz num único e mesmo sentido da substância, que é em si, e dos modos, que são em outra coisa. Com Espinosa, a univocidade se torna objeto de afirmação pura. [...]. E é na imanência que a univocidade encontrará sua fórmula propriamente espinosista. (DELEUZE, 1968b, p. 71)

O conceito espinosista de imanência não tem outro sentido: ele expressa a dupla univocidade da causa e dos atributos, ou seja, a unidade da causa eficiente com a causa formal, a identidade do atributo tal como constitui a essência da substância e tal como é implicado pelas essências das criaturas. (DELEUZE, 1968b, p. 182-183)
\end{abstract}

Outra maneira de abordar a imanência em Espinosa é a seguinte: a substância tem uma potência absolutamente infinita de existir e de agir e uma potência absolutamente infinita de pensar, que são ditas as duas metades do absoluto, e os modos participam destas potências, as criaturas são partes desta onipotência divina. Isso só é possível porque, para Espinosa, a essência é potência, o ser é afirmado como potência. A essência da substância é sua potência absolutamente infinita, as essências dos modos são os graus desta potência, graus de potência internos à potência absolutamente infinita da substância. Os modos expressam atualmente a substância por meio de suas potências. Os infinitos atributos, por sua vez, são as condições pelas quais a potência absolutamente infinita de existir e de agir é atribuída à substância por eles constituída, e os graus desta potência são atribuídos aos modos finitos neles contidos. Contudo, basta o atributo pensamento para que a potência absolutamente infinita de pensar seja atribuída à substância, assim como os graus desta potência, aos modos finitos. Em todo caso, "é por seus próprios atributos que Deus comunica a todas as criaturas a potência que lhes é própria” (DELEUZE, 1968b, p. 99).

\title{
O devir-expressivo das essências dos modos em Espinosa e o problema da expressão
}

Diante desta ontologia unívoca, imanente, expressiva de Espinosa, Leibniz faz uma interessante objeção, retomada por Deleuze (1968b, p. 354-355): se as 
essências dos modos já são atuais, eternas, perfeitas, e estão na substância como partes dessa substância, qual é o sentido da existência? Essa pergunta nos transporta para o terreno da ética, inseparável da ontologia em Espinosa. Deleuze se esforça para responder: ao nascermos, a potência do modo está envolvida, sua essência eterna, posta de maneira abstrata; para que ela se torne concreta e seja experimentada, é necessário ao modo se esforçar para ir ao máximo do que pode, desenvolver toda sua potência. Então, eventualmente, a essência do modo é efetuada, se torna expressiva, mesmo que momentaneamente.

Se a essência da substância envolve a existência da substância, se a substância existe necessariamente pela sua própria essência ou natureza, o mesmo não ocorre com os modos (ESPINOSA, c. 1667, parte I, proposições VII, XX e XXIV). As essências dos modos existem eternamente por sua causa, que é a substância, mas os modos podem ou não existir na duração: suas essências não envolvem suas existências. As essências dos modos são graus de potência ou partes intensivas que se relacionam intrinsecamente entre si, já que todas as essências dos modos estão contidas e complicadas nos atributos da substância. As existências dos modos, em compensação, contam com partes extensivas, que se relacionam extrinsecamente. Um modo passa a existir, ou nasce, quando à sua parte intensiva, à sua essência, começam a corresponder partes extensivas, subsumidas em uma certa relação característica. Estas partes extensivas, que se relacionam extrinsecamente, separam concretamente o modo de sua essência, de sua parte intensiva, do que ele pode: os choques entre elas não apenas impedem a ação do modo, a expressão de sua potência de existir e de agir, como também tornam parcial e mutilada a compreensão da relação interna com sua própria essência e com as demais essências dos modos, atrapalhando a expressão de sua potência de pensar. Por essa razão, os modos atravessam a maior parte de suas existências incapazes de expressar, ou tornar concretas, suas essências (DELEUZE, 1968b, p. 209-257).

Enquanto existe, o modo encontra outros modos, com cujas partes extensivas as suas próprias se chocam, se relacionam, de maneira extrínseca. Inicialmente nada compreende destes encontros ou de sua própria potência, da qual está separado. Por isso se fala em acaso dos encontros: não porque as partes extensivas se choquem ao acaso, já que tudo é necessário na natureza, mas porque é 
assim que parece aos modos, que nada conhecem das relações entre as partes extensivas (as leis de composição e decomposição da natureza) e da maneira como são produzidos nele os efeitos dos encontros com outros modos (as alegrias e tristezas). As ideias que forma, em tais circunstâncias, são inadequadas, parciais, mutiladas, visto que recolhem os efeitos, mas nada informam sobre suas causas. Tais ideias não expressam a potência de pensar do modo, que permanece em seu mais baixo grau. Os efeitos que lhes acometem são os afetos, variações de sua potência de agir e de pensar para mais (alegria) e para menos (tristeza). Estes afetos tampouco expressam a sua potência de existir e de agir, uma vez que têm uma causa externa. Se a essência do modo corresponde a um grau de potência, durante a existência, esse grau de potência é preenchido de maneiras diversas, e apenas quando é preenchido por ideias adequadas (que reúnem causa e efeito) e afetos ativos (alegrias ativas, causadas pelo próprio modo), há um devir-expressivo da essência do modo (DELEUZE, 1968b, p. 239-358).

No acaso dos encontros, as leis de composição e decomposição da natureza são ainda desconhecidas dos modos, e o modo faz ora bons encontros, em que se compõe com outros modos e sente alegria, ora maus encontros, em que é decomposto parcialmente e sente tristeza, ou ainda, decomposto totalmente, isto é, morre. Em ambos os casos, as ideias são inadequadas, pois o modo não conhece as causas do que ocorre, as leis da natureza, e os afetos são passivos, visto que não são causados pela potência de existir e de agir do próprio modo. Sua essência, portanto, permanece abstrata, inexpressiva. O modo só a expressa nas ocasiões em que tem ideias adequadas e afetos ativos (DELEUZE, 1968b, p. 239-358).

Respondendo a Leibniz a partir de elementos da filosofia espinosista, Deleuze (1968b, p. 339-358) defende que o sentido da existência é a busca pela expressividade da essência, a partir do esforço do modo para ir ao máximo do que pode. Neste esforço, às vezes acontece ao modo de, por um momento, experimentar que é eterno, sentir a coexistência da duração e da eternidade, de suas partes extensivas e de sua parte intensiva. Ele experimenta, então, sua própria essência eterna enquanto vive. São muito poucos os que conseguem conquistar essa eternidade durante a existência, embora por breves instantes. Em geral, os modos permanecem (quase) o tempo todo no acaso dos encontros. 
A perspectiva espinosista da imanência e da univocidade do ser fundamenta, portanto, uma ética igualmente imanente, que põe como única “obrigação" para o modo ir ao máximo do que pode, desdobrar sua potência, efetuar sua essência. Não se trata de comparar, em termos absolutos, os graus de potência, as essências dos modos, já que todos participam igualmente e imediatamente da potência de Deus, não havendo qualquer hierarquia ontológica entre eles. Entretanto, do ponto de vista ético, cabe estabelecer uma hierarquia, em que são selecionados como bons os modos que se esforçam para desdobrar suas potências, quaisquer que sejam elas, para efetuá-las, mesmo que por um breve momento, conquistando concretamente, durante a existência, suas eternidades, suas essências (DELEUZE, 1968a, p. 64, p. 67-68; 1968b, p. 300).

\section{Os três momentos da univocidade do ser em Diferença e repetição}

Como já mencionado, em Diferença e repetição, livro contemporâneo de Espinosa e o problema da expressão, Deleuze aborda o tema da univocidade e traça uma história em três capítulos - univocidade, imanência, diferença - dessa teoria ontológica. O primeiro se dá na Idade Média, com Duns Scot e a teoria do ser neutro; o segundo, com Espinosa e a teoria do ser imanente e expressivo; e o terceiro, com Nietzsche e a teoria do eterno retorno como ser da diferença.

Neste livro, Deleuze (1968a, p. 61) escreve: "Houve apenas uma proposição ontológica: o Ser é unívoco. Houve apenas uma ontologia, a de Duns Scot, que dá ao ser uma só voz." O modelo do juízo, aí exposto a partir de Aristóteles e de sua apropriação pela Escolástica, principalmente por São Tomás de Aquino, e responsável por instituir a teoria da analogia do ser, é substituído pelo modelo da proposição, de inspiração estoica, inaugurado por Duns Scot, e que instaura a univocidade do ser.

Neste modelo da proposição, há uma distinção decisiva entre a designação e a expressão. Por exemplo, ao olharmos o céu estrelado, vemos Vênus, que se torna especialmente brilhante pouco antes do nascer do sol e pouco depois do pôr do sol 
e, por esse motivo, é dita tanto estrela da manhã quanto estrela da tarde. Há, pois, dois nomes, duas expressões, estrela da manhã e estrela da tarde, para o mesmo designado, Vênus. Distintas expressões podem designar a mesma coisa. O que se observa igualmente no caso já exposto dos atributos, que são expressões que se distinguem formalmente, qualitativamente, e designam uma só coisa, a substância. Este modelo ontológico da proposição estabelece, portanto, que vários sentidos formalmente distintos se referem ao ser como a um único designado, ontologicamente uno (como na primeira tríade da expressão, já tratada acima). Ademais, o ser, como designado comum, se diz no mesmo sentido de todos os designantes ou expressantes numericamente distintos (a saber, os modos, tal como anteriormente apresentados na segunda tríade da expressão).

\begin{abstract}
O importante é que se possam conceber vários sentidos formalmente distintos, mas que se reportam ao ser como a um só designado, ontologicamente uno. [...]. É preciso acrescentar que o ser, o designado comum, enquanto se expressa, se diz, por sua vez, num único sentido de todos os designantes ou expressantes numericamente distintos. Na proposição ontológica, portanto, não só o designado é ontologicamente o mesmo para sentidos qualitativamente distintos, mas também o sentido é ontologicamente o mesmo para modos individuantes, para designantes ou expressantes numericamente distintos [...] o essencial na univocidade não é que o Ser se diga num único sentido. É que ele se diga, num único sentido, de todas as suas diferenças individuantes ou modalidades intrínsecas. (DELEUZE, 1968a, p. 62-63).
\end{abstract}

Em Duns Scot, o ser unívoco é neutro, uma vez que indiferente ao finito e ao infinito, ao singular e ao universal, ao criado e ao incriado. Se postulasse um mesmo ser para o infinito e o finito, o incriado e o criado, em suma, para Deus e as criaturas, recairia no panteísmo, o que, sendo um teólogo, evitou a todo custo. Em função deste risco, Duns Scot situou o ser aquém deste entrecruzamento do universal e do singular e fez dele um conceito neutro, abstrato. Por isso Deleuze (1968a, p. 66-67) diz que Duns Scot, conhecido como "doutor sutil", apenas pensa o ser unívoco: faz desse ser neutro, tomado como conceito abstrato, um mero objeto do pensamento.

Com Espinosa, o ser unívoco, definido como a substância única, universal e infinita, é finalmente afirmado: "deixa de ser neutralizado e se torna expressivo, se torna uma verdadeira proposição expressiva afirmativa." (DELEUZE, 1968a, p. 68) Embora se inspire, segundo Deleuze, nas teorias das distinções e da univocidade de Duns Scot, sendo neste sentido próximo ao teólogo medieval, Espinosa se afasta deste ao renovar 
essas mesmas teorias: a distinção formal passa a dizer respeito ao absoluto, e não apenas a seres de razão; e a univocidade não precisa mais expurgar o panteísmo, o que permite determinar e afirmar o conceito de ser unívoco como Deus sive Natura ${ }^{5}$. Para isso, Espinosa recorre à ideia de causa imanente (DELEUZE, 1968b, p. 55-71).

O que não impede Deleuze de fazer sua ressalva à versão espinosista da univocidade do ser. Mesmo avançando em relação a Duns Scot, ainda subsiste em Espinosa uma indiferença entre a substância e os modos: "a substância espinosista aparece independente dos modos, e os modos dependem da substância, mas como de outra coisa. Seria preciso que a própria substância fosse dita dos modos e somente dos modos" (DELEUZE, 1968a, p. 68). A identidade do ser na substância teria que se dizer da diferença dos modos: do devir, da multiplicidade dos modos que variam e se diferenciam incessantemente. A substância como identidade do ser teria que vir como segundo princípio, derivado da diferença modal.

A interpretação deleuziana do eterno retorno nietzschiano, terceira versão da teoria da univocidade, cumpre essa exigência ao trazer o ser como repetição da diferença: retornar é o ser do que se torna, revir é o ser do devir. A identidade do ser é a repetição, mas essa identidade se diz do que difere: o eterno retorno se diz da vontade de potência, do mundo das diferenças, das metamorfoses. O eterno retorno seleciona, neste mundo, o que retorna, e apenas as formas extremas como diferenças desdobradas em suas potências retornam, se repetem, realizam o ser unívoco. Assim, o eterno retorno nietzschiano realiza a univocidade do ser: nele, a identidade se diz da diferença, o ser se diz do devir, o uno se diz do múltiplo.

O eterno retorno, o revir, expressa o ser comum de todas as metamorfoses, a medida e o ser comum de tudo o que é extremo, de todos os graus de potência na medida em que são realizados. [...] o eterno retorno é a univocidade do ser, a realização efetiva dessa univocidade. No eterno retorno, o ser unívoco não é somente pensado, nem mesmo somente afirmado, mas efetivamente realizado. (DELEUZE, 1968a, p. 69)

\section{A ontologia construtivista em Espinosa: filosofia prática}

Em 1981, ou seja, treze anos após Espinosa e o problema da expressão e Diferença e repetição, Deleuze lança seu segundo livro dedicado ao pensamento de Espinosa,

\footnotetext{
${ }^{5}$ Para mais detalhes sobre como Espinosa se afasta da teologia negativa, se aproxima de Duns Scot e vai além deste, ver comentário de Hardt (1993, p. 63-66).
} 
Espinosa: filosofia prática, no qual busca pensar a filosofia prática de Espinosa, ou melhor, pensar a filosofia de Espinosa como prática. Isso não deve induzir ao erro de imaginar que alguma filosofia não seja prática: para Deleuze, toda filosofia é prática, e não há separação entre teoria e prática.

Outra maneira de colocar o problema é: que ontologia é correlata a uma filosofia prática, a uma filosofia que torna qualquer especulação secundária em relação a uma prática, seja predominantemente ética ou política? Seria uma ontologia da diferença, em que extraímos o ser das próprias variações, das diferenças que encontramos na dimensão prática? Tais indagações nos direcionam para um importante aspecto da filosofia de Espinosa, tal como a compreende Deleuze: a relação entre a ética, dimensão prática, e a ontologia.

Segundo Deleuze, Espinosa fundou e desenvolveu, pela primeira vez na história da filosofia ocidental, a relação entre ética e ontologia. Nesta perspectiva, só podemos pensar o esforço ético de um modo existente para ir ao máximo do que pode a partir de uma ontologia da imanência, em que o modo é um grau de potência no qual a substância se expressa. O modo só se esforça, durante a existência, para desdobrar sua potência, porque "precisa" efetuar sua essência. O sentido da existência do modo é efetuar sua essência. A ética não pode ser pensada sem a ontologia: há entre elas uma relação interna, que faz com que a ontologia seja o fundamento da ética em Espinosa. Portanto todas as teses práticas do espinosismo devem ser pensadas em relação com as teorias especulativas, e a alegria ética é o correlato da afirmação especulativa que observarmos na versão espinosista da univocidade do ser.

Contudo, ao ler Espinosa pela segunda vez, Deleuze lhe impõe uma torção: a ética não mais se funda na ontologia, porque as diferenças, as variações, são primeiras em relação ao ser. As variações afetivas dos modos são primeiras em relação à identidade da substância. Talvez se possa formular esta nova posição de Deleuze da seguinte maneira: a ética é a condição prática da ontologia. E o adjetivo "prática" aqui já adquire ares de redundância, pois tudo é prática em Deleuze, inclusive as condições.

É precisamente no capítulo 6 de Espinosa: filosofia prática, "Espinosa e nós", que Deleuze faz a dupla operação que torna possível uma nova relação entre ética e 
ontologia, segundo a qual a ética é condição prática da ontologia: ele faz da ética uma etologia e da ontologia um construtivismo. Fazer da ética uma etologia é deslocar tanto Deus quanto o homem do lugar de referência central para a ética. A etologia é, segundo o dicionário, o estudo do comportamento dos animais na relação com seu meio. Para Deleuze, no entanto: a etologia é "o estudo das relações de velocidade e de lentidão, dos poderes de afetar e de ser afetado que caracterizam cada coisa"; "a etologia estuda as composições de relações ou de poderes entre coisas diferentes” (DELEUZE, 1981, p. 130-131). A ética deve dar conta, então, dessas relações e desses poderes, que são as coordenadas do modo finito, dizem respeito à maneira como ele é composto por relações entre partes extensivas e como ele preenche seu poder de afetar e ser afetado. Por sua vez, fazer da ontologia um construtivismo é afirmar que a identidade do ser imanente não está dada: o ser precisa ser construído; a imanência é um plano que precisa ser traçado, um plano no sentido geométrico. E qual é a condição deste construtivismo? A ética. Em Deleuze, antes da ontologia, há a etologia, ou seja, a etologia orienta a ontologia.

O próprio Deleuze enuncia a pergunta que nos vem: "Em que consiste este plano e como construí-lo? Pois é ao mesmo tempo plenamente plano de imanência, e todavia deve ser construído, para que se viva de maneira espinosista." (DELEUZE, 1981, p. 127) Precisamos nos instalar no plano comum de imanência, em que estão os corpos. Eis o paradoxo: já estamos no plano de imanência, mas ainda precisamos nos instalar nele ${ }^{6}$. E como se define um corpo?

\begin{abstract}
Um corpo qualquer é definido por Espinosa de duas maneiras simultâneas. Por um lado, um corpo, por menor que seja, sempre comporta uma infinidade de partículas [de partes extensivas]: são as relações de repouso e de movimento, de velocidades e de lentidões entre partículas que definem um corpo, a individualidade de um corpo. Por outro lado, um corpo afeta outros corpos, ou é afetado por outros corpos: é o poder de afetar e de ser afetado que define assim um corpo em sua individualidade. Em aparência, são duas proposições muito simples: uma é cinética, e a outra é dinâmica. (DELEUZE, 1981, p. 128).
\end{abstract}

O corpo, assim como o plano de imanência, pode ser pensado a partir de eixos, de coordenadas. As proposições cinética e dinâmica traçam coordenadas para o corpo. Segundo sua longitude, o corpo se define pelas relações de movimento e

\footnotetext{
${ }^{6}$ Silva (2013, p. 106-107) indica como Deleuze recorre às filosofias não apenas de Espinosa, mas também de Bergson, para conceber o plano de imanência.
} 
repouso, de velocidade e lentidão entre as partes extensivas que a ele pertencem na duração, e não por formas desenvolvidas ou por funções orgânicas. Portanto, em seu eixo cinético, o corpo é ritmo. De acordo com sua latitude, o corpo é definido como um poder de afetar e ser afetado, como uma capacidade afetiva com um limiar máximo e um limiar mínimo, e não como uma substância ou um sujeito. Em seu eixo dinâmico, o corpo é, pois, afeto, devir. Assim, o corpo sempre varia, sempre se diferencia, seja como ritmo, seja como afeto.

A etologia fornece o exemplo. Como vive um carrapato? Aproximando Uexküll de Espinosa, Deleuze descreve o carrapato como tendo apenas três afetos: luminoso, olfativo, calorífico. Ao perceber a luz, o carrapato vai até o alto de um galho; ao sentir o cheiro de ácido butírico contido no suor dos mamíferos, ele se solta, podendo cair ou não sobre sua presa (se não obtiver sucesso, sobe novamente num galho); orientando-se pelo calor, busca uma região quente e sem pelo na pele do mamífero e se alimenta. Em seguida, se solta, põe seus ovos e morre, no que Uexküll (1956, p. 19) chama de banquete de morte. Este exemplo diz o que pode um carrapato, os afetos de que é capaz. Deleuze nos convida a pensar assim a ética do próprio homem.

\begin{abstract}
Isso vale tanto para nós, para os homens, quanto para os animais, visto que ninguém sabe de antemão os afetos de que é capaz, é uma longa questão de experimentação, é uma longa prudência, uma sabedoria espinosista que implica a construção de um plano de imanência ou de consistência. A Ética de Espinosa nada tem a ver com uma moral, é concebida como uma etologia, ou seja, como uma composição das velocidades e das lentidões, dos poderes de afetar e de ser afetado sobre esse plano de imanência. (DELEUZE, 1981, p. 130).
\end{abstract}

Mas como essa ética condiciona a ontologia, como os afetos conduzem ao ser? "Como indivíduos se compõem para formar um indivíduo superior, ao infinito?" Como constituir um mundo maior e mais intenso, um plano de imanência, um plano da Natureza, cujas partes variam de uma infinidade de maneiras? "O conjunto das longitudes e das latitudes constitui a Natureza, o plano de imanência ou de consistência, sempre variável, e que é incessantemente remanejado, composto, recomposto, pelos indivíduos e pelas coletividades". O plano de imanência é um plano de composição, e "o processo de composição deve ser apreendido por ele mesmo, através do que ele dá, no que ele dá” (DELEUZE, 1981, p. 131, p. 133). Apenas com essa concepção prática do plano se entende como 
passamos da ética à ontologia, da etologia à construção do plano de imanência, dos afetos ao ser. Por composição, sempre por composição: a composição dos modos, cada um em seu esforço para ir ao máximo do que pode, traça o plano de imanência, constrói o próprio ser.

\section{Conclusão: a natureza se afirma da diferença}

Leitor apaixonado de Espinosa, Deleuze faz dele um personagem muito presente em seu teatro filosófico, mas nem sempre o mesmo personagem. No que diz respeito à ontologia, em Espinosa e o problema da expressão, Espinosa é apresentado inicialmente como herdeiro de Duns Scot e segundo momento da teoria da univocidade do ser, à qual dá sua própria versão, a imanência expressiva, que faz do ser unívoco objeto de afirmação. Mas a exigência de que o ser se afirme da própria diferença é atendida apenas com o terceiro momento da univocidade do ser, o eterno retorno nietzschiano, tal qual lido por ele em Diferença e repetição. Deleuze não desiste, no entanto, de criar uma grande identidade Espinosa-Nietzsche em sua filosofia, e, em Espinosa: filosofia prática, transforma Espinosa em aliado de Nietzsche, ao compreender a imanência como um plano a ser construído. Nesta ontologia construtivista, por fim, a substância se diz dos modos, a natureza se afirma da diferença, e a univocidade do ser é realizada.

\section{Referências}

BADIOU, A. (1997) Deleuqe: la clameur de l'être. Paris: Hachette, 2009.

CHAUÍ, M. Intensivo e Extensivo na Ética de Espinosa: a interpretação dos modos finitos por Deleuze. In: FORNAZARI, S. K. (coord.); AZEVEDO, A. B. et al. (orgs.). Deleuze Hoje. São Paulo: Fap-Unifesp, 2014. p. 21-40.

CRAIA, E. A problemática ontológica de Gilles Deleuze. Curitiba: EdUnioeste, 2002.

DELEUZE, G. (1968a) Diferença e repetição. Tradução de Luiz Orlandi e Roberto Machado. São Paulo: Paz e Terra, 2018.

DELEUZE, G. (1968b) Espinosa: o problema da expressão. Tradução de GT Deleuze-12. São Paulo: Editora 34, 2017. 
DELEUZE, G. (1981) Espinosa: filosofia prática. Tradução de Daniel Lins e Fabien Pascal Lins. São Paulo: Escuta, 2002.

ESPINOSA, B. (c. 1677) Ética. Tradução do Grupo de Estudos Espinosanos. São Paulo: EdUSP, 2015.

HARDT, M. (1993) Gilles Deleuze: an apprenticeship in philosophy. Minneapolis: University of Minnesota Press, 2007.

MACHADO, R. Deleure, a arte e a filosofia. Rio de Janeiro: Zahar, 2009.

MONTEBELLO, P. Deleuze: la passion de la pensée. Paris: Vrin, 2008.

SILVA, C. V. Corpo e pensamento: alianças conceituais entre Deleuze e Espinosa. Campinas, SP: Editora da Unicamp, 2013.

UEXKÜLL, J. (1956) Mondes animaux et monde humain. Suivi de: La théorie de la signification. Paris: Denoël, 2004.

ZOURABICHVILI, F. (1994/2004) Deleuze. Une philosophie de l'événement. In: ZOURABICHVILI, F., SAVAGNARGUES, A., MARRATI, P. La philosophie de Deleuze. Paris: PUF, 2004.

RECEBIDO: $18 / 03 / 2019$

APROVADO: $14 / 06 / 2020$

RECEIVED: 03/18/2019

APPROVED: 06/14/2020 